\title{
Knowledge and Perception of Breast Density, Screening Mammography, and Supplemental Screening: in Search of "Informed"
}

\author{
Karen E. Schifferdecker, PhD, MPH ${ }^{1,2,3}$ (D), Anna N. A. Tosteson, ScD 1,2,4,5, \\ Celia Kaplan, Dr, $P H^{6}$, Karla Kerlikowske, MD $6,7,8,9$, Diana S.M. Buist, PhD, MPH ${ }^{10}$, \\ Louise M. Henderson, $\mathrm{PhD}^{17}$, Dianne Johnson ${ }^{12}$, Jill Jaworski ${ }^{12}$, Gloria Jackson-Nefertiti ${ }^{12}$, \\ Kelly Ehrlich, $\mathrm{MS}^{10}$, Mary W. Marsh, MPH ${ }^{17}$, Lisa Vu, MPH', Tracy Onega, PhD, MS 2,4, 13,14, \\ and Karen J. Wernli, PhD ${ }^{10}$
}

\begin{abstract}
'Department of Community and Family Medicine, Geisel School of Medicine at Dartmouth, Lebanon, NH, USA; ${ }^{2}$ The Dartmouth Institute for Health Policy and Clinical Practice, Geisel School of Medicine at Dartmouth, Lebanon, NH, USA; ${ }^{3}$ Center for Program Design and Evaluation at Dartmouth (CPDE), Lebanon, NH, USA; ' ${ }^{2}$ epartment of Medicine, Geisel School of Medicine at Dartmouth, Lebanon, NH, USA; ${ }^{5}$ Norris Cotton Cancer Center, Geisel School of Medicine at Dartmouth and Dartmouth-Hitchcock Health System, Lebanon, NH, USA; ${ }^{6}$ Department of Medicine, University of California, San Francisco, CA, USA; ${ }^{7}$ Department Epidemiology and Biostatistics, University of California, San Francisco, CA, USA; ${ }^{8}$ General Internal Medicine Section, University of California, San Francisco, CA, USA; 'Department of Veterans Affairs, University of California, San Francisco, CA, USA; ${ }^{10}$ Kaiser Permanente Washington Health Research Institute, Seattle, WA, USA; " 1 Department of Radiology, University of North Carolina, Chapel Hill, NC, USA; ${ }^{12}$ Department of Public Health Sciences, University of California, Davis, Davis, CA, USA; ${ }^{13}$ Department of Biomedical Data Science, Geisel School of Medicine at Dartmouth, Lebanon, NH, USA; ${ }^{14}$ Department of Epidemiology, Geisel School of Medicine at Dartmouth, Lebanon, NH, USA.
\end{abstract}

BACKGROUND: As of 2019, 37 US states have breast density notification laws. No qualitative study to date has examined women's perspectives about breast density in general or by states with and without notification laws. OBJECTIVE: Explore women's knowledge and perceptions of breast density and experiences of breast cancer screening across three states with and without notification laws.

DESIGN: Qualitative research design using four focus groups conducted in 2017.

PARTICIPANTS: Forty-seven women who had a recent normal mammogram and dense breasts in registry data obtained through the Breast Cancer Surveillance Consortium.

APPROACH: Focus groups were $90 \mathrm{~min}$, audio recorded, and transcribed for analysis. Data were analyzed using mixed deductive and inductive coding.

KEY RESULTS: Women reported variable knowledge levels of personal breast density and breast density in general, even among women living in states with a notification law. A number of women were aware of the difficulty of detecting cancer with dense breasts, but only one knew that density increased breast cancer risk. Across all states, very few women reported receiving information about breast density during healthcare visits beyond being encouraged to get supplemental imaging or to pay for new mammography technology (i.e., breast tomosynthesis). Women offered more imaging or different technology held strong convictions that these were "better," even though knowledge of differences, effectiveness, or harms across technologies seemed limited. Women

Received July 24, 2019

Accepted November 13, 2019

Published online December 2, 2019 from all states expressed a strong desire for more information about breast density.

CONCLUSIONS: More research needs to be done to understand how the medical community can best assist women in making informed decisions related to breast density, mammography, and supplemental screening. Options to explore include improved breast density notifications and education materials about breast density, continued development of personalized risk information tools, strategies for providers to discuss evidence and options based on risk stratification, and shared decision-making.

KEY WORDS: screening; breast cancer; qualitative; patient preferences; patient education.

J Gen Intern Med 35(6): 1654-60

DOI: $10.1007 /$ s11606-019-05560-Z

(C) Society of General Internal Medicine 2019

\section{BACKGROUND}

Information continues to emerge on women's health and risks related to breast density and breast cancer. Dense breasts, which are often classified as heterogeneously or extremely dense breast tissue using the Breast Imaging Reporting and Data System, ${ }^{1}$ are an independent risk factor, and one of the strongest for breast cancer. ${ }^{2-4}$ Breast density, which is assessed on a mammogram, may also mask breast cancer resulting in reduced mammography performance. ${ }^{5,}{ }^{6}$ Breast density was not typically shared with women nor the increased risk it confers until breast density legislation. Thus, women were mostly unaware of their own breast density or how this may affect their health. 
To overcome this gap in knowledge and awareness for women, 37 (74\%) states have passed breast density notification laws. Connecticut was the first state to pass legislation in 2009 due to the work of advocacy groups, which mandated notification of breast density for women undergoing mammography. ${ }^{7}$ Since then, 36 additional states have passed notification laws but these vary in terms of the depth of notification required and the understandability of the information provided. ${ }^{8,9}$ For instance, some states inform women of their breast density category and others only inform women about breast density in general but not their own breast density. ${ }^{10} \mathrm{In}$ addition, research on the actual dense breast notifications from 23 states revealed that readability scores were a mean 10.5 grade level and understandability scores were poor. ${ }^{9}$

With variable laws and notification requirements across states, the impact on women's knowledge and awareness is also variable. A 2016 literature review of women's knowledge and awareness of breast density identified five cross-sectional studies conducted in medical clinics or through online services. ${ }^{11}$ Summary results indicated that women aged 40 years and older have a moderate awareness of breast density, but a low proportion knew their own breast density or had knowledge about breast density's influence on breast cancer risk and detection. Only one qualitative study ${ }^{12}$ has examined women's perspectives about breast density knowledge, notification letters, and recommendations. Klinger et al. ${ }^{12}$ evaluated women's and clinicians' perspectives on breast density in an urban hospital setting in Boston. Results from focus groups indicated that women had little knowledge of the breast density notification laws. Women reported they preferred notification and discussion from sources that they trusted. ${ }^{12}$ No qualitative study to date has examined women's perspectives about breast density in general or by states with and without breast density notification laws.

\section{OBJECTIVE}

To address this gap, we conducted a qualitative study to explore women's knowledge and perceptions of breast density and experiences of breast cancer screening in relation to breast density. We included women across three states with varying notification laws, to understand women's knowledge, comprehension, desires, and concerns regarding breast density.

\section{DESIGN}

We conducted a qualitative study as part of a larger study on breast density being conducted by the Breast Cancer Surveillance Consortium (BCSC). ${ }^{13}$ The BCSC is a network of breast imaging registries that link breast imaging data from community-based radiology facilities to state, regional, or Surveillance, Epidemiology, and End Results cancer registries and pathology databases. We conducted the study in 2017 through three BCSC registries in three states which differed in their state-mandated breast density notification laws. The first state (Washington) had no notification law at the time of the focus groups. The second state (California) had a law enacted in 2013 where breast density notifications indicate if a woman has dense breasts but not which category of breast density and also notifies her that density is an independent risk factor for breast cancer. The third state (North Carolina) had a law enacted in 2014 where breast density notifications indicate if a woman has dense breasts, which category of breast density she has (heterogeneous or extremely dense), that density may make it more difficult to identify abnormalities or cancer (masking), and that it is an independent risk factor for breast cancer. $^{14}$

Each registry received institutional review board approval for recruitment and consent into the study. All procedures were Health Insurance Portability and Accountability Act compliant.

\section{PARTICIPANTS}

The three participating BCSC registries identified potential women in their own registry. Eligible women were those aged 40-80 years who had a digital screening mammogram with a normal result in the previous 12 months and were identified to have heterogeneously or extremely dense breasts, as defined by radiologists' reporting using the Breast Imaging Reporting and Data System density categories. ${ }^{1}$ Women were excluded if they had previously been diagnosed with breast cancer. Sampling was also set to try and recruit women who had or had not received supplemental screening imaging (either breast MRI or digital breast tomosynthesis). Eligible women were sent a recruitment letter and asked to contact the respective registry program manager if they were interested in participating.

\section{APPROACH}

We developed a focus group interview guide to discuss: reasons for undergoing breast cancer screening, knowledge of breast cancer risk factors, information received and knowledge of breast density, including their own breast density, and experiences with and questions about mammograms, supplemental imaging, and breast density. One author (KES), an experienced qualitative researcher and focus group facilitator, drafted the focus group guide, which was then reviewed by five other researchers experienced in breast cancer research and health services, to ensure relevance of the questions.

We conducted four focus groups based on guidance for reaching thematic saturation ${ }^{13}$ and ensured consistency by having all the focus groups led by the same facilitator (KES). One to two patient advisors to the research study (DJ, JJ, GJN) and one to two additional researchers (KK, $\mathrm{DB}, \mathrm{LH}, \mathrm{KW}$ ) were present at each focus group to assist in facilitation and as note-takers. We obtained written informed 
consent before each session, had women complete a brief demographic survey, and provided an incentive of $\$ 75$.

All of the focus groups were audiotaped, transcribed, and imported into Dedoose, a qualitative data analysis program. ${ }^{15}$ Two authors (KES, KW) developed the codebook, themes and analytic strategy through a mixed deductive (directed content analysis) and inductive (grounded theory) approach. ${ }^{16,17}$ Specifically, we pre-determined some codes based on the main research questions and developed additional codes based on an iterative review of the data and emerging themes. The codes were reviewed by two additional authors (AT, CK) and revised to incorporate their feedback. Disagreements on coding were discussed and resolved through consensus. Two researchers (KES, KW) then grouped the codes into themes and discussed these with the research team to reach congruency. Notably, our research team included our three patient partners (DJ, JJ, GJN), who observed the focus groups and reviewed the themes, to ensure the validity and relevance of our findings.

\section{KEY RESULTS}

A total of 47 women participated in the four focus groups ranging in size from 10 to 14 participants. By state, 14 (30\%) of women were from WA (no notification law), 12 (25\%) were from CA (notification of dense breasts), and 21 (45\%) were from NC (notification of breast density category). Table 1 provides demographic information on the focus group participants.

The final code book consisted of 39 codes, which we applied to 443 excerpts and resulted in six main themes. These

Table 1 Focus Group Participant Characteristics, $N=43$

\begin{tabular}{lll}
\hline \hline Mean age $=\mathbf{5 8}$ (range $\mathbf{4 0 - 8 0 )}$ & $\mathbf{N}$ & $\mathbf{\%}$ \\
\hline Race & & 7 \\
Asian & 3 & 19 \\
Black or African American & 8 & 4 \\
Hispanic or Latino & 2 & 70 \\
White & 30 & \\
Education & & 2 \\
Some high school, but did not graduate & 1 & 2 \\
High school graduate or GED & 1 & 47 \\
Some college or 2-year degree & 20 & 33 \\
4-year college graduate & 7 & 7 \\
More than 4-year college degree & 14 & 11 \\
Annual income $(n=27)^{\dagger}$ & & 15 \\
Less than \$15,000 & 2 & 15 \\
\$15,000 to \$24,999 & 3 & 11 \\
\$25,000 to \$49,999 & 4 & 41 \\
\$50,000 to \$74,999 & 4 & 33 \\
\$75,000 to \$99,000 & 3 & 14 \\
\$100,000 or more & 11 & 37 \\
Working status & & 5 \\
Full-time & 14 & 9 \\
Part-time & 6 & \\
Retired & 16 & \\
Unemployed & 2 & \\
Unable to work & 4 & \\
Homemaker/keeping house & & \\
\hline
\end{tabular}

4 participants did not provide information

HIncome not asked at one BCSC registry site included (1) knowledge and understanding of breast density, (2) information received about breast density, (3) questions or concerns about breast density and screening, (4) experiences with screening and supplemental imaging, including social influence, (5) desire for more information, and (6) financial concerns.

\section{KNOWLEDGE AND UNDERSTANDING OF BREAST DENSITY}

Overall, only 23 women (49\%) knew that they had dense breasts although all of them were recruited based on having dense breasts. Of those who knew, most found out either through a mammography notification letter or from a health care professional, including mammography technologists. Being from a state with a notification law (CA or $\mathrm{NC}$ ) did not increase the likelihood that women knew if they had dense breasts, since more than half of women from WA (no notification law) knew they had dense breasts compared with half or less from $\mathrm{CA}$ and $\mathrm{NC}$.

"I don't know what dense breasts are. I guess I don't have them."

Though knowledge of personal breast density differed, a majority of the women seemed to be aware that women can have different levels of breast density; however, most had limited knowledge of what this meant. For women who knew something about breast density in general, most were aware of the potential difficulty of mammograms detecting cancer with increasing density, but only one woman across all four focus groups described it as an independent risk factor for breast cancer.

"That's all I know about dense breasts. I guess it makes them hard to see through."

"Not like if you have dense breasts you're going to get cancer. I've never heard like it increases the risk, it's just that sometimes the abnormalities go unnoticed."

\section{INFORMATION RECEIVED ABOUT BREAST DENSITY}

Information received about breast density was an additional major theme related to knowledge of breast density. Regardless of which state they lived in, most women described receiving little to no detailed information or education at the time of screening or from providers about breast density aside from being told that it may make it harder to read a mammogram. In addition, none of the 47 women reported receiving any written or online educational materials related to breast density beyond what was provided in the notification letter.

"About a year after I had my last child was the very first time I was ever told that I had dense breast tissue and it 
would make it fairly difficult to read it (mammogram). And I went - okay. And that's basically been it. It's never been fully explained to me."

"What is this density? It's not blood. I don't know what we're really talking about, the density. And my doctor says stay off the internet for me in particular, because it's kind of a black hole."

"It was explained to me at one time about density. I was like 'well, what is that all about?' And she said 'it's kind of like having scar tissue or something like that, where it's really, really thick, thicker than normal, and you can't see through it."'Some women described looking information up online but this did not appear to be something that most of the women had done. Lastly, although the notification letter was a recognized as a source of information for some women, no one talked about breast density notification laws suggesting a lack of awareness of these laws.

\section{QUESTIONS OR CONCERNS ABOUT BREAST DENSITY AND SCREENING}

Across all three states, there were three times as many excerpts related to questions or concerns about breast density, including implications for breast cancer screening, compared with excerpts indicating that a woman was satisfied with what they knew.

"Is it hereditary? Do you grow into having dense breasts?"

"So it (breast density) was never really explained. Is this a good thing? Is this a bad thing? Is this just a nothing?"

"Don't most people have dense breasts? I mean, I just thought it was the norm, to me like it was a compliment. You know? I thought it was pretty normal. I don't know what the percentage is of how many people have dense breasts."

A related area was questions or concerns about mammography and trust in the results. Although there was a range of opinions about digital mammography results, from trusting this imaging modality to detect breast cancer to not trusting it, $49 \%$ of women were already receiving other types of imaging, either digital breast tomosynthesis (DBT) or supplemental screening described in more detail below. Similar to breast density, however, women appeared to have limited knowledge about other types of breast imaging and were not getting much information about one screening test compared with another, including potential harms, aside from being told or assuming that some tests would make it easier to find potential cancer.

\section{EXPERIENCES WITH SCREENING FOR BREAST CANCER AND SUPPLEMENTAL IMAGING, INCLUDING SOCIAL INFLUENCE}

When describing screening for breast cancer, almost half of the women $(N=23,49 \%)$ talked about getting DBT instead of digital mammography or receiving some kind of supplemental imaging, including ultrasound or breast MRIs. Although our respondents are not a representative sample of women from these states, all descriptions by women of being offered DBT were in NC, while receiving routine MRIs in addition to mammograms was only described by women from CA or WA.

Women from NC who described getting DBT, which is often called "3D" mammography, were almost all offered it as an alternative to digital mammography and were told they had to pay extra. They described it as a choice although the messaging related to DBT appeared to suggest that DBT was more accurate than digital mammography or better able to find breast cancer. In addition, there was no indication that women were informed of both the potential harms and benefits of choosing DBT.

"The receptionist came out, she said, 'Would you like to do 3D for $\$ 50$ more?' I'm like, 'I don't know would I?' I had no basis to even have it. But she said the cutting edge thing, and I'm Miss Star Trek, so I said 'okay, we'll do that."'

"She would say okay, do you want the 3D. So it didn't feel like a sales pitch. It was almost like 'do you want fries with that' kind of thing. Like we have it to offer... it wasn't like 'oh my God, fifty more dollars,' to me. It was like if you want this, you should have the ability to have this if you want it, because this is just another way for us to find something that might be hiding for folks like yourself with the dense tissue. So I never felt pressured or anything. I was happy that the information was there and she was like, 'if you want the 3D that's great, if you don't, that's okay too, but we have it.' And I was of course on that band wagon, so I jumped right on that."

"Facilitator: What did they tell you about this 3-D what information did they tell you about it in terms of Respondent: Nothing.

Facilitator: Nothing? Okay. So you knew -

Respondent: Just because I know that it (3-D) caught it for a friend of mine."

Around $15 \%$ of all the women were receiving supplemental screening, which included breast MRIs or breast ultrasounds on a fairly regular basis in addition to their routine digital mammograms. Most of these women described getting these at the recommendation of their providers based on family history, genetics, and/or dense breasts. A few other women, though, expressed concerns or questioned whether they should 
be getting supplemental screening given individuals in their social networks who were getting these imaging options.

"I have friends who also have the same condition (dense breasts), and they go in and they've had the MRI. I believe I asked about that, and I was wondering too if that was better, and who gets that."

"I guess I wonder - so my mother doesn't have the BRCA mutation, I get it from my father's side, but she's been told she has dense breasts. I've been told I have dense breasts. So she alternates with an ultrasound, and I wonder why that hasn't been something that's been recommended for me."Other women described lobbying to receive supplemental screening based on social influence, including direct recommendations from friends or others.

"Facilitator: So how did you know about the ultrasound? Did you ask for that? Were you offered that?

Respondent: No - I have a girlfriend who does mammography so she's like 'shoot for that.' My provider was fine with putting in a referral for me to take it, because then I was losing sleep, because I'm like 'oh my goodness, what do you mean?' So I had ultrasound. Facilitator: So you got the (notification) letter that said it can't all be found, and then you had -

Respondent: Yeah, I think they worded it like ten percent, I think is the percentage that was listed on the letter. So that's when I said I want to request to have an ultrasound done.

Facilitator: And your girlfriend was the one that told you about that?

Respondent: Yeah."Among women being offered DBT or requesting supplemental screening, they expressed strong convictions that this would be "better" for them and more likely to ensure that they did not have breast cancer or that it would be found earlier.

"3-D looks cooler than 2-D. So yeah, I want a color picture of my boob. I didn't know how much easier, better or more specific that was, but I was willing to do it, feeling that if they're offering it, it must be better."

\section{DESIRE FOR MORE INFORMATION}

Similar to questions and concerns about breast density and screening and across all three states, most of the women wanted more information related to breast density and implications for screening. Several women described being satisfied, trusting their providers, and feeling assured by the results from their screening mammography.
However, most expressed concern that they had not received more information.

"Why is breast density important? I notice a long time ago, I got a letter from them...Yeah, I like this information and I would love to know what's going on in my care."

"My letter left me a little more confused because it said it was normal but that I did have dense breast tissue. So now what? You know, there's no follow up, there's no questions until I go again, a year later.”

\section{FINANCIAL CONCERNS}

For the most part, women did not express concerns about paying for mammography, including DBT, or supplemental imaging. A few women, however, talked about significant concerns related to receiving breast MRIs as part of their recommended screening and having their insurance refuse to cover it.

[In relation to getting MRIs]. "But it's still very stressful every time you go and I have no idea what my bill is going to be. And that's very concerning."

"And the doctor had actually ordered an MRI, but the insurance denied it. Even though I have the history of cancer in the family and I have the density and all, they still denied letting me have one.... And that's an expense that's kind of hard to take out of your pocket."

\section{CONCLUSIONS}

Our findings are consistent with survey research related to breast density in that women were moderately aware of their own breast density. ${ }^{10}$ Unlike other research, ${ }^{18}$ our participants largely did not know that breast density is an independent risk factor for breast cancer and being a resident in a state with a notification law did not appear to help women know more about breast density. Given the relatively high education levels of our sample (i.e., $49 \%$ had a college degree or higher) and the fact that $70 \%$ of our women came from states with notification laws, this was somewhat surprising. However, research on the understandability and readability of breast density notifications ${ }^{9}$ and our own finding of limited information being provided to women about breast density or supplemental screening suggest that this may not be uncommon.

One potential avenue to increase women's knowledge and understanding of breast density in states with notification laws is to create notification standards and improve content so every woman who chooses to have a mammogram gets information about her own density in a way that she can use. ${ }^{9}$ An additional strategy across all states is to provide quality education materials on breast density. Unfortunately, communicating what the information means for individual women and 
potential next steps complicates notifications and provision of education materials since informed decisions should ideally be based on personal breast density combined with other breast cancer risk factors and discussions with their providers. ${ }^{19}$ One tool to provide personalized risk information based on the BCSC's breast cancer risk calculator in combination with breast density notification improved women's knowledge and recognition of risk and prompted them to discuss options with their primary care providers (PCP) ${ }^{20}$ More research is needed to understand the tool's usefulness for women from a variety of backgrounds, how prepared PCPs or other providers are to answer questions or assist women in making decisions, ${ }^{21-23}$ and impacts on subsequent screening.

Our findings also suggest that there is insufficient information related to both DBT and supplemental screening. In our study, women's perception of breast imaging and technology that are "better" for them indicate a general lack of awareness of the performance of medical imaging, and that mammography is able to detect breast cancer in women with dense breasts. ${ }^{6}$ At the same time, research related to current breast density notifications has shown increased use of supplemental screening, ${ }^{24}$ which may or may not be covered by insurance. ${ }^{14}$ This supplemental screening can lead to more false-positive results, unnecessary procedures, financial costs, and anxiety for women. ${ }^{25}$ While increased use of supplemental screening is justified for some women given their overall breast cancer risk, a large number are most likely due to insufficient understanding of risks, benefits, and potential harms on the part of women and their providers. ${ }^{20-22}$

In light of this information, what might be a way forward to both inform women about breast density and assist them in making informed decisions? Along with notifications or educational materials that provide information about breast density and personal breast density that is understandable, Slanetz et al. ${ }^{25}$ propose a combination of "risk stratification" and a consensus by the medical community "on how best to advise women with dense breasts with regard to the limitations of various screening tests and the role of any supplemental screening. Then, practitioners could base patient care on existing evidence and each woman's individual risk." Recent research suggests that at least some women are open to discussing screening based on their risk, including potential benefits and harms, and making decisions with their providers, ${ }^{26}$ which supports the approach suggested by Slanetz. ${ }^{25}$

Based on our findings with women from diverse backgrounds and previous research, we suggest additional research to understand how the medical community can best assist women in making informed decisions related to dense breasts and screening. Notable options to consider include improved breast density notifications, high quality educational materials about breast density, continued development of tools to provide personalized risk information, identifying strategies for providers and other healthcare team members to discuss evidence and options based on risk stratification, and shared decision-making with women. ${ }^{27}$ If we can make progress on identifying the best approaches, women then have a better chance of making an informed choice for themselves, allowing us to hopefully both "maximize cancer detection and minimize the downsides of screening." 25

Acknowledgments: The authors wish to thank all our research partners in the Breast Cancer Surveillance Consortium who collaborated on participant recruitment and implementation of the focus groups. We are especially grateful to all the women who participated in the focus groups. We thank the participating women, mammography facilities, and radiologists for the data they have provided for this study. A list of the BCSC investigators is provided at: http://www. bcsc-research.org/.

Corresponding Author: Karen E. Schifferdecker, PhD, MPH; Center for Program Design and Evaluation at Dartmouth (CPDE), Lebanon, NH, USA (e-mail: Karen.E.Schifferdecker@dartmouth.edu).

Funding Information Research reported in this work was funded through a Patient-Centered Outcomes Research Institute (PCORI) award (PCS-1504-30370). Data collection for this research was additionally supported by the Breast Cancer Surveillance Consortium with funding from the National Cancer Institute (P01CA154292, U54CA163303).

\section{Compliance with Ethical Standards:}

Conflict of Interest: The authors have no conflicts of interest.

Disclaimer: The statements presented in this work are solely the responsibility of the authors and do not necessarily represent the official views of PCORI, its Board of Governors or Methodology Committee, the National Cancer Institute, or the National Institutes of Health.

\section{REFERENCES}

1. D'Orsi C, Sickles E, Mendelson E, Morris E, et al. ACR BI-RADS ${ }^{\circledR}$ Atlas, Breast Imaging Reporting and Data System. 5th ed. Reston, VA: American College of Radiology; 2013. https://www.acr.org/Quality-Safety/Resources/BIRADS.

2. Harvey JA, Bovbjerg VE. Quantitative assessment of mammographic breast density: Relationship with breast cancer risk. Radiology. 2004;230(1):29-41. doi:https://doi.org/10.1148/radiol.2301020870

3. McCormack VA, Dos Santos Silva I. Breast density and parenchymal patterns as markers of breast cancer risk: A meta-analysis. Cancer Epidemiol Biomark Prev 2006;15(6):1159-1169. doi:https://doi.org/10. 1158/1055-9965.EPI-06-0034

4. Boyd NF, Rommens JM, Vogt $\mathbf{K}$, et al. Mammographic breast density as an intermediate phenotype for breast cancer. Lancet Oncol 2005;6(11):826.

5. Kerlikowske $\mathbf{K}, \mathbf{Z h u} \mathbf{W}$, Tosteson AN, et al. Identifying women with dense breasts at high risk of interval cancers: A cohort study. Ann Intern Med 2015;162(10):673-681. doi:https://doi.org/10.1016/j.pecs.2004. 02.004

6. Kerlikowske $\mathbf{K}$, Hubbard RA, Miglioretti DL, et al. Comparative effectiveness of digital versus film-screen mammography in community practice in the United States: A cohort study. Ann Intern Med 2011;155(8):493-502.

7. Cappello NM. Decade of 'normal' mammography reports-The Happygram. J Am Coll Radiol 2013; 10(12):903-908.

8. DenseBreast-info I. Legislation and regulations -What is required? https://densebreast-info.org/legislation.aspx. Published 2019.

9. Kressin N, Gunn C, Battaglia T. Content, readability, and understandability of dense breast notifications by state. Jama. 2016;315(23):26242624.

10. Cappello NM, Richetelli D, Lee CI. The impact of breast density reporting laws on women's awareness of density-associated risks and 
conversations regarding supplemental screening with providers. $J A m$ Coll Radiol 2019;16(2):139-146. doi:https://doi.org/10.1016/j.jacr. 2018.08.009

11. Santiago-Rivas M, Benjamin S, Jandorf L. Breast density knowledge and awareness: A review of literature. J Prim Care Community Health 2016;24(10):e321-e326. doi:https://doi.org/10.1007/s13187-013-04571

12. Klinger E V, Kaplan CP, Birdwell RL, Haas JS. Patient and provider perspectives on mammographic breast density notification legislation. MDM Policy Pract 2016;1:1-8. doi:https://doi.org/10.1177/ 2381468316680620

13. Breast Cancer Surveillance Consortium (BCSC). http://www.bcsc-research.org/index.html. Accessed August 12, 2018.

14. DenseBreast-info. Comparative Analysis of State Density Inform Efforts and Insurance Coverage. https://densebreast-info.org/img/comparative-analysis-state-density-inform-efforts-insurance-coverage.pdf. Published 2019. Accessed January 2, 2019.

15. Dedoose Version 6.1.18, web application for managing, analyzing, and presenting qualitative and mixed method research data. 2016. Los Angeles, CA: SocioCultural Research Consultants, LLC. www.dedoose. com.

16. Corbin J, Strauss A. Basics of Qualitative Research: Techniques and Procedures for Developing Grounded Theory. 3rd ed. 2008. Thousand Oaks: Sage Publications Inc.

17. Hsieh HF, Shannon SE. Three approaches to qualitative content analysis. Qual Health Res 2005;15(9):1277-1288. doi:https://doi.org/ $10.1177 / 1049732305276687$

18. Rhodes DJ, Breitkopf CR, Ziegenfuss JY, Jenkins SM, Vachon CM. Awareness of breast density and its impact on breast cancer detection and risk. J Clin Oncol 2015;33(10):1143-1150. doi:https://doi.org/10. 1200/JCO.2014.57.0325

19. Haas JS, Kaplan CP. The divide between breast density notification laws and evidence-based guidelines for breast cancer screening: Legislating practice. JAMA Intern Med 2015;175(9):1439-1440. doi:https://doi.org/ 10.1001/jamainternmed.2015.3040

20. Haas J, Giess C, Harris K, Ansolabehere J, Kaplan CP. Randomized Trial of Personalized Breast Density and Breast Cancer Risk Notification. J Gen Intern Med. 2019;34(4):591-597. doi:https://doi.org/10.1007/ s11606-018-4622-4

21. Gunn CM, Kressin NR, Cooper K, Marturano C, Freund KM, Battaglia TA. Primary care provider experience with breast density legislation in Massachusetts. J Women's Health. 2018;27(5):615-622. https://doi.org/ 10.1089/jwh.2017.6539.

22. Khong KA, Hargreaves J, Aminololama-Shakeri S, Lindfors KK. Impact of the California breast density law on primary care physicians. J Am Coll Radiol 2015;12(3):256-260. doi:https://doi.org/10.1016/j. jacr.2014.09.042

23. Maimone S, McDonough M, Hines S. Breast Density Reporting Laws and Supplemental Screening-A Survey of Referring Providers' Experiences and Understanding. Curr Probl Diagn Radiol 2017;46(2):105-109. doi:https://doi.org/10.1067/j.cpradiol.2016.05.001

24. Houssami $\mathbf{N}$, Lee $\mathbf{C I}$. The impact of legislation mandating breast density notification - Review of the evidence. Breast. 2018;42:102-112. doi:https://doi.org/10.1016/j.breast.2018.09.001

25. Slanetz PJ, Freer PE, Birdwell RL. Breast-Density legislation Practical considerations. N Engl J Med 2015;372(7):593-595.

26. He X, Schifferdecker KE, Ozanne EM, Tosteson ANA, Woloshin S, Schwartz LM. How do women view risk-based mammography screening? A qualitative study. J Gen Intern Med 2018;33(11):1905-1912. doi:https://doi.org/10.1007/s11606-018-4601-9

27. Keating NL, Pace LE. Breast Cancer Screening in 2018. Jama. 2018;319(17):1814. doi:https://doi.org/10.1001/jama.2018.3388

Publisher's Note Springer Nature remains neutral with regard to jurisdictional claims in published maps and institutional affiliations. 